\title{
Interactions of atrazine with transition metal ions in aqueous media: experimental and computational approach
}

\author{
Vijay Kumar • Virender Kumar • Niraj Upadhyay • \\ Sitansh Sharma
}

Received: 18 November 2014/ Accepted: 27 January 2015/Published online: 6 February 2015

(c) The Author(s) 2015. This article is published with open access at Springerlink.com

\begin{abstract}
Transition metal ions have their own significances and utility. Externally applied pesticides may alter the bioavailability of these metal ions to plants through the coordinating ability of these pesticides with metal ions. In current study a series of metal complexes containing atrazine (Atr) group(s) attached to metal(II) (M) frame, with the formula; $\left[\mathrm{M}(\mathrm{Atr})_{\mathrm{n}} \cdot \mathrm{xH}_{2} \mathrm{O} \cdot \mathrm{yCl}\right]$ (where $\mathrm{M}=\mathrm{Mn}, \mathrm{Fe}, \mathrm{Co}, \mathrm{Ni}, \mathrm{Cu}$ or $\mathrm{Zn} ; n=1$ or $2 ; x=1-4$; $y=1-2$ ), have been synthesized for the first time to check the interactions of atrazine with transition metal ions. More importantly, all the complexes were synthesized at neutral $\mathrm{pH}$ in aqueous medium. The major differences among the FTIR spectra were observed between 3,700-2,800 and $1,800-1,350 \mathrm{~cm}^{-1}$. On the basis of FTIR, CHN and computational study, it was observed that $\mathrm{Mn}, \mathrm{Ni}$ and $\mathrm{Cu}$ formed complexes in 1:2 and $\mathrm{Fe}, \mathrm{Co}$ and $\mathrm{Zn}$ in 1:1. The obtained results were supported by $3 \mathrm{D}$ molecular modeling using GAMESS computations as a package of ChemBio3D Ultra14 program. The FTIR spectral analysis and 3D molecular modeling suggests that the Atr can show coordination through the nitrogen (in between two side chains) of ring as well as nitrogen (non steric amine) of side chain with different metal ions.
\end{abstract}

\footnotetext{
V. Kumar · V. Kumar · S. Sharma

Department of Chemistry, Lovely Professional University, Phagwara 144002, Punjab, India

N. Upadhyay $(\bowtie)$

Department of Chemistry, Dr. Hari Singh Gour University,

Sagar, Madhya Pradesh, India

e-mail: nivij.res@gmail.com
}

Keywords Atrazine - Metal complex · FTIR analysis · Water of hydration $\cdot$ Chelation

\section{Introduction}

2-chloro- $N^{4}-N^{6}$-isopropyl-1,3,5-trizine-4,6-diamine or atrazine (Atr) is a broad spectrum herbicide (EPA 2005; Meng and Carper 2000). It inhibits photosynthesis and interferes with other enzymatic processes of weeds. It is the member of triazine family and it is still used in about 90 countries all over the world (EPA 2005; Meng and Carper 2000). Annual use of atrazine was estimated to be 80,000 tons worldwide. Since, it is the well-known fact that transport of pesticides in environment occurs by their electrical potentials, adsorption and complex-formation powers (Kumar et al. 2013a, b; Kumar et al. 2014; Meng and Carper 2000; Prasad et al. 2013), same may be applicable for atrazine too.

Atr previously has been the theme of theoretical metal complex studies (Meng and Carper 2000). Theoretical studies show that atrazine can form complexes with different metal ions that are one metal ion to one Atr molecule (1:2) and one metal ion to two Atr molecules (1:2). Such metal to Atr complexes may include water of hydration coordinated to the metal ions in complexes. The formation of dimers suggests that, there is a chance of metal complex formation. As per our best information, no experimental study on transition metal complex of Atr is reported in literature. Because of diverse applications of transition metal ions like $\mathrm{Mn}, \mathrm{Fe}, \mathrm{Co}, \mathrm{Ni}$, $\mathrm{Cu}, \mathrm{Zn}$ for the healthy growth of plants and humans, therefore, it is found interesting to investigate the complexation of Atr with series of divalent transition metal ions. 


\section{Experimental}

Material and instruments

All the chemicals used were analytical reagent grade. The complexes were prepared as procedure described below. The C, H, N analysis for all the samples were carried out. The FTIR spectra of $\mathrm{KBr}$ discs were recorded on a Shimadzu-8400 s FTIR spectrophotometer. To collect good resolution and fine spectra of synthesized metal complexes, each and every time $1 \mathrm{mg}$ of each product was added to $100 \mathrm{mg}$ of $\mathrm{KBr}$. To weigh the above mentioned quantity of metal complex and $\mathrm{KBr}$, weighing balance with five digits was used.

All the FTIR spectra including spectra of Atr were compared to each other using ATR spectral analysis. For the comparative ATR analysis of metal-Atr complexes with Atr, all the FTIR spectra were set to baseline and converted to ATR spectra using FTIR software tool of Shimadzu-8400 s FTIR spectrophotometer.

Procedure to synthesize atrazine-metal ions complexes

Aqueous solution $(10 \mathrm{ml})$ of metal salts $(1 \mathrm{mM})$ was added to ethanolic solution $(10 \mathrm{ml})$ of atrazine $(2 \mathrm{mM})$, the $\mathrm{pH}$ of reaction mixture was adjusted at $\sim 7$ using $\mathrm{NaOH}$ solution. The resulting solution was stirred for $3 \mathrm{~h}$ on a magnetic stirrer at $70{ }^{\circ} \mathrm{C}$, followed by concentrating it to one-third of its volume. Fine amorphous products were collected, washed with hot water (to remove unreacted metal ions) followed by ethanol (to remove unreacted atrazine or also act as drying agent), dried in vacuum desiccator (to remove excess water content) and allowed for FTIR and elemental analysis. After performing the solubility test of the synthesized complexes it was observed that complexes were partially soluble in chloroform and DMSO only. The melting points of all the complexes were between 190 and $260{ }^{\circ} \mathrm{C}$.

Molecular modeling studies

An attempt to gain a better insight on the molecular structure of Metal complexes, geometric optimization and conformational analysis has been performed by the use of Merck Molecular Force Field 94 (MMFF94) program (Esperdy and Shillady 2007; Hakobyan et al. 2014). All the calculations refer to isolated molecules in vacuum. To calculate the above mentioned parameters, executable program file of GAMESS (Cambridge Software ChemBio3D Ultra 14.0.) program was run on PC (Esperdy and Shillady 2007; Hakobyan et al. 2014).

\section{Result and discussion}

The comparative FTIR spectra of Atr and its metal complexes have shown the shifting in wavenumber and decrease of intensity in the stretching band of the $v(\mathrm{NH})$, and $v(\mathrm{CN})$ at 3,320-3,210 \& 1,650-1,585, and 2,190-2,050 \& 1,110-1,010 $\mathrm{cm}^{-1}$ (Fig. 1; Table 1). The IR spectra of complexes were showing absorption bands centered at $683-412 \mathrm{~cm}^{-1}$, indicating the presence of $\mathrm{M}-\mathrm{N}$ and $\mathrm{M}-\mathrm{O}$ bonds (metal water bond) (Fig. 1; Table 1). Also, strong absorptions bands observed for all the complexes at $750-840 \mathrm{~cm}^{-1}$ were due to the "out of plane" (oop) vibrations of the $\mathrm{NH}$ of Atr. Moreover, a strong absorption band at 710-560 $\mathrm{cm}^{-1}$ for complexes was due to an $\mathrm{O}-\mathrm{M}-$ $\mathrm{N}$ stretching vibration, indicating an $\mathrm{O}-\mathrm{M}-\mathrm{N}$ bonding or water-M-Atr bonding (Nakamoto 1986).

On the basis of FTIR spectral features (Table 1; Fig. 1), it was observed that all the FTIR spectra were different over two ranges, these ranges were $3,700-2,800 \mathrm{~cm}^{-1}$ and 1,800-1,350 $\mathrm{cm}^{-1}$ (Figs. 2, 3). Atrazine has five nitrogen atoms each having a lone pair of electrons to donate. First of all it is necessary to determine whether the coordination occurs through the ring nitrogen or side chain(s) nitrogen or both of them are involved in complex formation. The ring nitrogen (between two substituents at 4th and 6th position of ring) is known to be more basic in comparison to the amino nitrogen. It is a known fact that when the amino or side chain(s) nitrogen atom is involved in complex formation, drastic changes occur in amino group

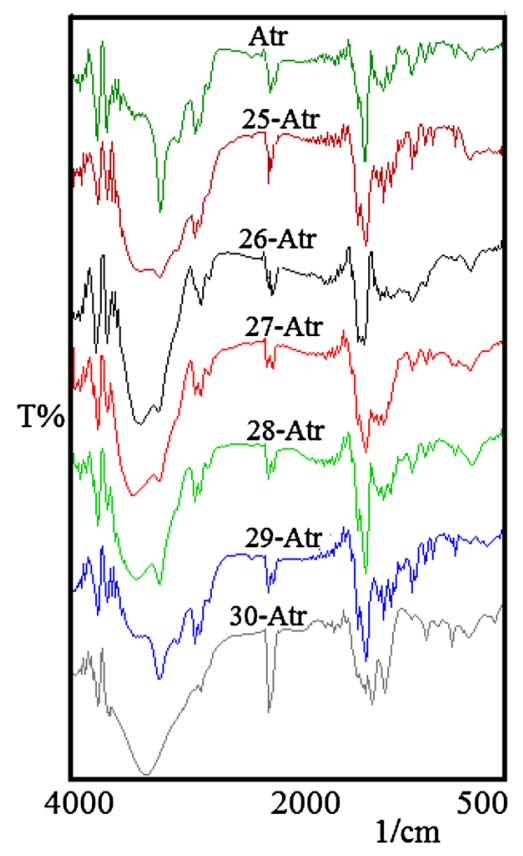

Fig. 1 FTIR spectra of atrazine metal complexes 
Table 1 Change in vibrational frequencies of Atrazine after metal complexation

\begin{tabular}{|c|c|c|c|c|c|c|c|}
\hline Assignment & Atr & Mn-Atr & Fe-Atr & Co-Atr & Ni-Atr & $\mathrm{Cu}-\mathrm{Atr}$ & Zn-Atr \\
\hline$v(\mathrm{O}-\mathrm{H})$ & - & $3,422^{\mathrm{m}}$ & $3,414^{\mathrm{sh}}$ & $3,481^{\mathrm{m}}$ & - & $3,460^{\mathrm{m}}$ & $3,439^{\mathrm{b}}$ \\
\hline \multirow[t]{2}{*}{$v(\mathrm{~N}-\mathrm{H})$} & $3,261^{\mathrm{vs}}$ & $3,265^{\mathrm{vs}}$ & $3,269^{\mathrm{vs}}$ & $3,265^{\mathrm{vs}}$ & $3,265^{\mathrm{m}}$ & $3,261^{\mathrm{s}}$ & - \\
\hline & $3,115^{\mathrm{w}}$ & $3,120^{\mathrm{w}}$ & $3,110^{\mathrm{sh}}$ & $3,120^{\mathrm{sh}}$ & $3,119^{\mathrm{w}}$ & $3,115^{\text {sh }}$ & - \\
\hline \multirow[t]{3}{*}{$v(\mathrm{C}-\mathrm{H})$} & $2,974^{\mathrm{m}}$ & $2,972^{\mathrm{s}}$ & $2,968^{\mathrm{m}}$ & $2,972^{\mathrm{m}}$ & $2,974^{\mathrm{m}}$ & $2,974^{\mathrm{m}}$ & $2,983^{\mathrm{m}}$ \\
\hline & $2,929^{\mathrm{m}}$ & $2,931^{\mathrm{m}}$ & $2,926^{\mathrm{m}}$ & $2,928^{\mathrm{m}}$ & $2,931^{\mathrm{w}}$ & $2,929^{\mathrm{m}}$ & $2,926^{\mathrm{w}}$ \\
\hline & $2,854^{\mathrm{w}}$ & $2,862^{\mathrm{m}}$ & $2,860^{\mathrm{m}}$ & $2,858^{w}$ & $2,862^{\mathrm{w}}$ & $2,852^{\mathrm{vw}}$ & $2,860^{\mathrm{w}}$ \\
\hline$\delta(\mathrm{N}-\mathrm{H}) \mathrm{v}_{1}$ & $1,666^{\mathrm{m}}$ & $1,660^{\mathrm{vs}}$ & $1,666^{\mathrm{sh}}$ & $1,666^{\mathrm{sh}}$ & $1,660^{\mathrm{sh}}$ & $1,668^{\mathrm{sh}}$ & $1,664^{\mathrm{sh}}$ \\
\hline$\delta(\mathrm{OH}) \mathrm{v}_{2}$ & $1,620^{\mathrm{vs}}$ & $1,616^{\mathrm{vs}}$ & $1,614^{\mathrm{vs}}$ & $1,616^{\mathrm{m}}$ & $1,616^{\mathrm{m}}$ & $1,622^{\mathrm{m}}$ & $1,627^{\text {sh }}$ \\
\hline \multirow[t]{2}{*}{$v(\mathrm{C}=\mathrm{N}) \mathrm{v}_{3}$} & $1,575^{\mathrm{vs}}$ & $1,575^{\mathrm{vs}}$ & $1,591^{\mathrm{vs}}$ & $1,568^{\mathrm{vs}}$ & $1,575^{\mathrm{vs}}$ & $1,562^{\mathrm{sh}}$ & $1,588^{\mathrm{sh}}$ \\
\hline & $1,558^{\mathrm{vs}}$ & $1,558^{\mathrm{s}}$ & $1,572^{\mathrm{vs}}$ & - & $1,558^{\mathrm{vs}}$ & $1,548^{\mathrm{vs}}$ & $1,558^{\mathrm{m}}$ \\
\hline \multirow[t]{5}{*}{$\delta(\mathrm{C}-\mathrm{H})$} & $1,481^{\mathrm{s}}$ & $1,475^{\mathrm{m}}$ & $1,475^{\text {sh }}$ & $1,477^{\mathrm{s}}$ & $1,475^{\mathrm{sh}}$ & - & $1,491^{\mathrm{m}}$ \\
\hline & $1,440^{\mathrm{s}}$ & $1,450^{\mathrm{m}}$ & $1,425^{\text {sh }}$ & $1,437^{\mathrm{s}}$ & $1,450^{\mathrm{m}}$ & $1,442^{\mathrm{m}}$ & - \\
\hline & $1,404^{\mathrm{s}}$ & $1,400^{\mathrm{m}}$ & $1,363^{\mathrm{sh}}$ & $1,398^{\mathrm{m}}$ & $1,400^{\mathrm{m}}$ & $1,404^{\mathrm{m}}$ & $1,398^{\mathrm{w}}$ \\
\hline & $1,346^{\mathrm{s}}$ & $1,342^{\mathrm{s}}$ & - & $1,342^{\mathrm{sh}}$ & $1,342^{\mathrm{m}}$ & $1,346^{\mathrm{w}}$ & - \\
\hline & $1,303^{\mathrm{m}}$ & $1,131^{\mathrm{m}}$ & $1,307^{\text {sh }}$ & - & $1,315^{\text {sh }}$ & $1,305^{\mathrm{w}}$ & - \\
\hline \multirow[t]{2}{*}{$v(\mathrm{C}-\mathrm{NH})$} & $1,166^{\mathrm{s}}$ & $1,165^{\mathrm{m}}$ & $1,151^{\mathrm{b}}$ & $1,166^{\mathrm{w}}$ & $1,168^{\mathrm{m}}$ & $1,169^{\mathrm{w}}$ & $1,168^{\mathrm{w}}$ \\
\hline & $1,134^{\mathrm{w}}$ & $1,132^{\mathrm{w}}$ & - & $1,139^{\mathrm{sh}}$ & $1,134^{\mathrm{w}}$ & $1,132^{\mathrm{sh}}$ & - \\
\hline$v(\mathrm{C}-\mathrm{N})$ & $1,055^{\mathrm{s}}$ & $1,053^{\mathrm{s}}$ & $1,049^{\mathrm{s}}$ & $1,049^{\mathrm{m}}$ & $1,053^{\mathrm{w}}$ & $1,053^{\mathrm{m}}$ & $1,045^{\mathrm{m}}$ \\
\hline Ring breath & $991^{\mathrm{s}}$ & $991^{\mathrm{w}}$ & $989^{\mathrm{sh}}$ & $989^{w}$ & $991^{\mathrm{w}}$ & $991^{\mathrm{m}}$ & $949^{w}$ \\
\hline $\operatorname{oop}(\mathrm{N}-\mathrm{H})$ & $804^{\mathrm{m}}$ & $804^{w}$ & $798^{\text {sh }}$ & $800^{\mathrm{w}}$ & $802^{w}$ & $804^{w}$ & $831^{\mathrm{w}}$ \\
\hline$\gamma(\mathrm{C}-\mathrm{H})$ & $723^{\mathrm{m}}$ & - & - & $710^{\mathrm{w}}$ & - & - & $734^{w}$ \\
\hline$v(\mathrm{C}-\mathrm{Cl})$ & $677^{\mathrm{m}}$ & $684^{\mathrm{b}}$ & $667^{\mathrm{b}}$ & $677^{\mathrm{b}}$ & $657^{\mathrm{b}}$ & $678^{\text {sh }}$ & $680^{\mathrm{b}}$ \\
\hline$\delta$ (ring) $\mathrm{v}_{4}$ & $533^{\mathrm{m}}$ & - & $549^{\text {sh }}$ & $547^{\mathrm{w}}$ & $549^{w}$ & - & $520^{\mathrm{w}}$ \\
\hline \multirow[t]{3}{*}{$\mathrm{M}-\mathrm{CN}$} & - & $2,182^{\mathrm{m}}$ & $2,185^{\mathrm{m}}$ & $2,183^{\mathrm{w}}$ & - & - & - \\
\hline & - & $2,095^{\mathrm{m}}$ & $2,095^{\mathrm{m}}$ & $2,098^{w}$ & - & - & - \\
\hline & - & $2,041^{\mathrm{m}}$ & $2,045^{\mathrm{w}}$ & $2,044^{\mathrm{m}}$ & - & - & - \\
\hline $\mathrm{M}-\mathrm{N}$ & - & 535 & 486 & 522 & 493 & 592 & 474 \\
\hline $\mathrm{M}-\mathrm{O}$ & - & 432 & 451 & 439 & 418 & 442 & 414 \\
\hline
\end{tabular}

$s$ strong, $v s$ very strong, $b$ broad, $v b$ very broad, $s h$ shoulder, $m$ medium, $w$ weak

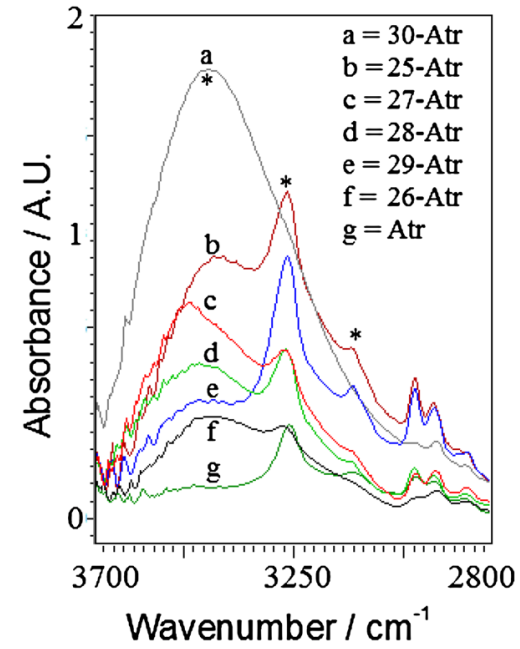

Fig. 2 Qualitative change in absorption of Atrazine-metal complexes between 3,700 and $2,800 \mathrm{~cm}^{-1}$

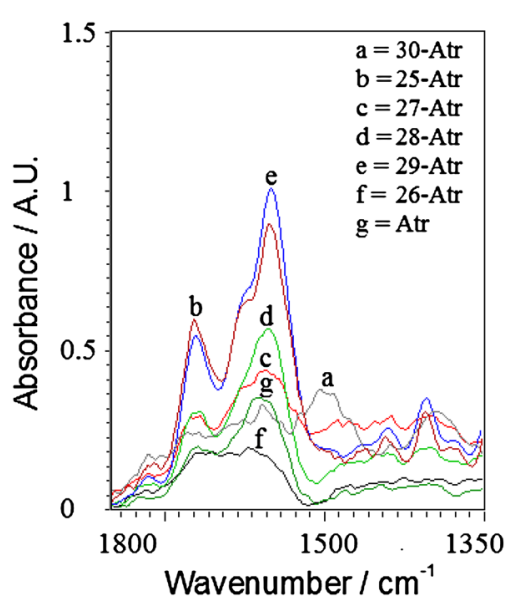

Fig. 3 Quantitative change in absorption of Atrazine-metal complexes between 1,800 and $1,350 \mathrm{~cm}^{-1}$ 
vibrational wave numbers, namely, $\mathrm{NH}$ stretching and bending modes shift to lower wave numbers, whereas $\mathrm{NH}$ twisting and wagging modes shift to higher wave numbers. On the other hand when the ring nitrogen is involved in complex formation certain vibrational modes increase in value due to both coupling with $\mathrm{M}-\mathrm{N}$ bond vibrations and alterations of the force field (Medlycott et al. 2008). Especially the main changes have taken place in the stretching frequencies of $\mathrm{C}=\mathrm{N}$.

IR-ATR analysis over a range of $3,700-2,800 \mathrm{~cm}^{-1}$

On the basis of Fig. 2 and Table 2, there were three peaks observed at 3,454, 3,266 and $3,124 \mathrm{~cm}^{-1}$ due to stretching frequencies of $\mathrm{OH}$ and $\mathrm{NH}$. The $\mathrm{OH}$ stretching frequencies at $3,454 \mathrm{~cm}^{-1}$ was due to the presence of water molecules. The NH stretching frequencies at 3,266 and $3,124 \mathrm{~cm}^{-1}$ were due to the presence of secondary amines of Atr molecules. ATR analysis at $3,454 \mathrm{~cm}^{-1}$ has shown that $\mathrm{Zn}$ Atr has highest absorption or water molecules and Fe-Atr has lowest absorption or water molecules. The order of absorption of metal-Atr complexes at $3,454 \mathrm{~cm}^{-1}$ is; $\mathrm{Zn}>\mathrm{Mn}>\mathrm{Co}>\mathrm{Cu}>\mathrm{Ni}>\mathrm{Fe}$ (Fig. 2). IR frequencies in metal complexes at 3,787 and $3,705 \mathrm{~cm}^{-1}$ were due to the water of crystal and at $3,454 \mathrm{~cm}^{-1}$ was due to the water of coordination. ATR analysis at 3,266 and 3,124 $\mathrm{cm}^{-1}$ has shown that Mn-Atr has highest absorption or minimum involvement of $\mathrm{NH}$ of Atr and Fe-Atr has lowest absorption or highest involvement of $\mathrm{NH}$ of Atr. The order of absorption of metal-Atr complexes at 3,266 and 3,124 $\mathrm{cm}^{-1}$ is; $\mathrm{Mn}>\mathrm{Zn}>\mathrm{Cu}>\mathrm{Co} \sim \mathrm{Ni} \gg \mathrm{Fe}$ (Fig. 2).

FTIR analysis over a range of $1,800-1,350 \mathrm{~cm}^{-1}$

On the basis of Fig. 3 and Table 2, there were two peaks observed at 1,622 and $1,550 \mathrm{~cm}^{-1}$ due to bending frequencies of $\mathrm{NH}$ and stretching frequencies of $\mathrm{C}=\mathrm{N}$. The trends of vibrational modes of metal complexes were very

Table 2 Quantitative change in vibrational frequencies of atrazine after metal complexation w.r.t. Abs

\begin{tabular}{lllllll}
\hline M-Atr & \multicolumn{7}{l}{ Abs. (AU) at different frequencies } \\
\cline { 2 - 7 } & 3454 & 3266 & 3124 & 1622 & 1577 & 1550 \\
\hline $\mathrm{Mn}$ & 1.01 & 1.28 & 0.67 & 0.58 & 0.64 & 0.89 \\
$\mathrm{Fe}$ & 0.41 & 0.37 & $0.18^{*}$ & 0.17 & 0.17 & 0.15 \\
$\mathrm{Co}$ & 0.99 & 0.67 & 0.27 & 0.28 & 0.38 & 0.42 \\
$\mathrm{Ni}$ & 0.61 & 0.67 & 0.22 & 0.30 & 0.39 & 0.56 \\
$\mathrm{Cu}$ & 0.48 & 1.07 & 0.52 & 0.54 & 0.66 & 1.01 \\
$\mathrm{Zn}$ & 1.76 & $1.16^{*}$ & $0.52^{*}$ & 0.24 & 0.28 & 0.30 \\
$\mathrm{Atr}$ & 0.12 & 0.31 & 0.15 & 0.19 & 0.62 & 0.33 \\
\hline
\end{tabular}

* Not sharp peaks, but only shoulder observed similar to the order of stretching frequencies at $\mathrm{NH}$. As mentioned above $\mathrm{C}=\mathrm{N}$ is more basic in nature and it can coordinate easily with different metal ions. FTIR analysis at $1,550 \mathrm{~cm}^{-1}$ has shown that $\mathrm{Cu}$-Atr has highest absorption and Fe-Atr has lowest absorption. The order of absorption of metal-Atr complexes at $1,550 \mathrm{~cm}^{-1}$ is; $\mathrm{Cu}>\mathrm{Mn}>\mathrm{Ni}>\mathrm{Co}>\mathrm{Zn}>\mathrm{Fe}$ (Fig. 3). At $1,622 \mathrm{~cm}^{-1}$ the exact order of absorption is; $\mathrm{Mn}>\mathrm{Cu}>\mathrm{Ni}>$ Co $>\mathrm{Zn}>\mathrm{Fe}$. Similarly at $1,622 \mathrm{~cm}^{-1}$ the exact order of absorption is; $\mathrm{Cu}>\mathrm{Mn}>\mathrm{Ni}>\mathrm{Co}>\mathrm{Zn}>\mathrm{Fe}$.

\section{Structure prediction}

From the analysis of all FTIR spectra, it is quite clear that there was involvement of crystalline $\left(3,750-3,600 \mathrm{~cm}^{-1}\right)$ and coordinated $\left(3,500-3,430\right.$ and $\left.1,625 \mathrm{~cm}^{-1}\right)$ water molecules in the atrazine-metal complexes. To confirm the stoichiometry as well the presence of water and chloride ions, CHN analysis was also done (Table 3). It was observed that with $\mathrm{Mn}$ (II), Atr formed octahedral complex and coordinated through the $\mathrm{C}=\mathrm{N}$ of ring. Here chlorine and water molecules are also acting as coordinated ions. $\mathrm{Fe}(\mathrm{II})$ ion has formed the distorted square planer complex in $1: 1$ where chlorine and water molecules were acting as coordinated ions. Co(II) ion has formed 1:1 distorted octahedral complex and coordinated through the $\mathrm{C}=\mathrm{N}$ of ring and $\mathrm{NH}$ of side chain. Here chlorine and water molecules are also acting as coordinated ions. $\mathrm{Ni}(\mathrm{II})$ ion has formed the distorted square planer complex in 1:1 where chlorine and water molecules were acting as coordinated ions. $\mathrm{Cu}(\mathrm{II})$ ion has formed the distorted tetrahedral complex in 1:2 where chlorine and water molecules were acting as coordinated ions. $\mathrm{Zn}$ (II) ion has formed the distorted tetrahedral complex in 1:1 where only water molecules were acting as coordinated ions (Table 3 ).

In previous experimental and theoretical studies of metal ions to atrazine, the complexation was affected by the water of hydration significantly, because, water molecule under high $\mathrm{pH}$ (5-8) values can act as good ligand, and in the presence of bulky molecules, it becomes more active to show coordination with metal ions (Martin et al. 1998; Medlycott et al. 2008; Meng and Carper 2000). The geometry, coordination and water of hydration of current study are very similar to previous experimental and theoretical studies. In previous experimental study, it observed that the metal ions were interacted to triazine (member of atrazine family) through the least bulky side chain nitrogen due to the steric effect of side chains (Martin et al. 1998; Medlycott et al. 2008; Meng and Carper 2000). In various theoretical studies it was mentioned that atrazine can form complex with transition and non-transition metal ion with variable number of atrazine and water molecules (Martin et al. 1998; Medlycott et al. 2008; Meng and Carper 2000). 
Table 3 Most probable structures of metal complexes and CHN analysis

\begin{tabular}{|c|c|c|c|c|c|c|c|c|}
\hline \multirow[t]{3}{*}{ Metal ion } & \multirow[t]{3}{*}{ Molecular formula } & \multirow[t]{3}{*}{ Structure* } & \multicolumn{6}{|c|}{$\mathrm{CHN}$ analysis $(\%)$} \\
\hline & & & \multicolumn{3}{|l|}{ Cal. } & \multicolumn{3}{|l|}{ Obs. } \\
\hline & & & $\mathrm{C}$ & $\mathrm{H}$ & $\mathrm{N}$ & $\mathrm{C}$ & $\mathrm{H}$ & $\mathrm{N}$ \\
\hline $\mathrm{Mn}$ & {$\left[\mathrm{Mn}(\mathrm{Atr})_{2} \cdot\left(\mathrm{H}_{2} \mathrm{O}\right)_{2}(\mathrm{Cl})_{2}\right] \cdot 2 \mathrm{H}_{2} \mathrm{O}^{\mathrm{a}}$} & Octahedral & 30.53 & 5.77 & 22.26 & 31.12 & 5.42 & 22.88 \\
\hline $\mathrm{Fe}$ & {$\left[\mathrm{Fe}(\mathrm{Atr}) \cdot(\mathrm{Cl})_{2}\right] \cdot 2 \mathrm{H}_{2} \mathrm{O}^{\mathrm{b}}$} & Square planar & 25.39 & 4.79 & 18.50 & 25.56 & 4.65 & 18.59 \\
\hline Co & {$\left[\mathrm{Co}(\mathrm{Atr}) \cdot\left(\mathrm{H}_{2} \mathrm{O}\right)_{2}(\mathrm{Cl})_{2}\right] \cdot 2 \mathrm{H}_{2} \mathrm{O}^{\mathrm{b}}$} & Octahedral & 23.01 & 5.31 & 16.77 & 23.14 & 5.36 & 16.68 \\
\hline $\mathrm{Ni}$ & {$\left[\mathrm{Ni}(\mathrm{Atr}) \cdot\left(\mathrm{H}_{2} \mathrm{O}\right)(\mathrm{Cl})\right] \cdot 2 \mathrm{H}_{2} \mathrm{O}^{\mathrm{b}}$} & Square planar & 26.41 & 5.54 & 19.31 & 26.32 & 5.61 & 19.33 \\
\hline $\mathrm{Cu}$ & {$\left[\mathrm{Cu}(\mathrm{Atr})_{2} \cdot(\mathrm{Cl})_{2}\right] \cdot 2 \mathrm{H}_{2} \mathrm{O}^{\mathrm{a}}$} & Tetrahedral & 31.93 & 5.36 & 23.27 & 31.83 & 5.41 & 23.58 \\
\hline $\mathrm{Zn}$ & {$\left[\mathrm{Zn}(\mathrm{Atr}) \cdot\left(\mathrm{H}_{2} \mathrm{O}\right)_{2}\right] \cdot 2 \mathrm{H}_{2} \mathrm{O}^{\mathrm{b}}$} & Tetrahedral & 27.21 & 6.28 & 19.83 & 27.33 & 6.22 & 19.78 \\
\hline
\end{tabular}

a Where Atr coordinated with metal ion(s) from $\mathrm{CN}$ side

b Where Atr coordinated with metal ion(s) from $\mathrm{CN}$ and $\mathrm{NH}$ side

* Most probable geometry

We have no particular explanation behind these structure arrangements, but it is quite understandable that if atrazine is forming monomeric complex with metal ion, the number of water molecules will increase. In liquid media (chloroform) metal effect of atrazine on the metal complexes of cadmium or copper or lead or zinc to 1-phenyl-3-methyl-4p-tertbutylbenzoyl-5-hydroxypyrazole was studied (Martin et al. 1998; Medlycott et al. 2008; Meng and Carper 2000). It was observed that under liquid media (chloroform), atrazine can form complex with cadmium, copper and zinc with an order; $\mathrm{Cd}>\mathrm{Zn}>\mathrm{Cu}$, this depends on the nature of the metal. In theoretical studies, it also has assumed that under liquid media (water) atrazine interacts with cadmium, copper and zinc by replacing one of the water molecules of the solvatation sphere. That mechanism might be explained by the "hard-soft theory" arguing that "soft" nitrogen atoms of atrazine have stronger interactions with "soft" cations (Martin et al. 1998; Medlycott et al. 2008; Meng and Carper 2000).

It is known that s-triazines (member of atrazine family) can be adsorbed on clay minerals as both protonated and neutral species. A comparison of the infrared spectra of atrazine adsorbed on montmorillonite with the spectrum of an acid solution of atrazine in water also revealed the presence of protonated species on the surface (Herwig et al. 2001; Bailey et al. 1968; Martin et al. 1998; Medlycott et al. 2008; Meng and Carper 2000). The sorption mechanism discussed was a cation exchange of the protonated species. Thus, in this case as well as for the iondipole or coordination-type interactions, it is to be assumed that the kind of surface cation plays a key role in the adsorption process. It was reported that at neutral $\mathrm{pH}$ iondipole interactions are in dominancy and coordination-type interactions under acidic conditions (Herwig et al. 2001; Bailey et al. 1968; Martin et al. 1998; Medlycott et al. 2008; Meng and Carper 2000).
Molecular modeling

Since our trials to obtain a single crystals of the metal complexes were unsuccessful so far, and to gain a better understanding of geometrical structures of the investigated complexes, molecular modeling studies have been done by means of GAMESS (Cambridge Software ChemBio3D Ultra 14.0.) program package. Some selected bond lengths and angles are listed in Table 4; the optimized structures, with atom-labeling scheme, of complexes 1-6 are represented in Fig. 4. The complexes feature four and six coordinated metal centers with $\mathrm{N}$ of ring, $\mathrm{N}$ of side chain, $\mathrm{Cl}$ and $\mathrm{H}_{2} \mathrm{O}$ molecules. For complexes 1 and 5, the manganese and copper atoms are forming complexes with two Atr ligands through the $\mathrm{N}$ of ring. Whereas, for complexes 2,3 , 4 and 6, the metals are forming complexes with one Atr through the $\mathrm{N}$ of ring and $\mathrm{N}$ of less bulky chain including $\mathrm{Cl}$ and $\mathrm{H}_{2} \mathrm{O}$ as additional ligands to stabilize the metal complexes. The cis angles around the metal ions are variable, range from $74.17^{\circ}$ to $99.34^{\circ}$, respectively; the trans angles ranging from $130.26^{\circ}$ to $162.53^{\circ}$, respectively, indicating octahedral to square planar geometry with tetrahedral distortion (Al-Assy et al. 2013; Azahari et al. 2014; Bonora et al. 2013; de-Melo et al. 2014; Dong et al. 2014; Girichev et al. 2010; Kanagathara et al. 2013; Moghaddamand Foroushani, 2014; Yaremenko et al. 2008). For all complexes, the dihedral coordination around the metal center, involving $\mathrm{O}, \mathrm{N}$ and $\mathrm{Cl}$ atoms is distorted. The degree of distortion from ideal tetrahedral geometry is given by the minimum and maximum coordination angles around metal ion. From Table 4, it is clear that the bond lengths are found to be within the normal ranges obtained from the crystal structure data of few nitrogen-based derivatives like triazines (Al-Assy et al. 2013; Azahari et al. 2014; Bonora et al. 2013; de-Melo et al., 2014; Dong et al. 2014; Girichev et al. 2010; Kanagathara et al. 2013; 
Table 4 3D computational optimized bond lengths and bond angles of metal-atrazine complexes

\begin{tabular}{|c|c|c|c|c|}
\hline \multirow[t]{2}{*}{ Complex } & \multicolumn{2}{|l|}{ Bond length $/ \mathrm{A}^{\mathrm{o}}$} & \multicolumn{2}{|l|}{ Bond angle/degree $\left({ }^{\circ}\right)$} \\
\hline & Atoms & Bond length & Atoms & Bond angle \\
\hline \multirow[t]{15}{*}{$\operatorname{Mn}(\mathrm{II})$} & $\mathrm{C}(2)-\mathrm{N}(3)$ & 1.283 & $\mathrm{~N}(3)-\mathrm{Mn}(29)-\mathrm{O}(32)$ & 83.861 \\
\hline & $\mathrm{C}(2)-\mathrm{N}(7)$ & 1.276 & $\mathrm{~N}(3)-\mathrm{Mn}(29)-\mathrm{O}(33)$ & 83.252 \\
\hline & N(17)-Mn(29) & 1.883 & N(3)-Mn(29)-Cl(30) & 159.693 \\
\hline & $\mathrm{N}(3)-\mathrm{Mn}(29)$ & 1.882 & $\mathrm{~N}(3)-\mathrm{Mn}(29)-\mathrm{Cl}(31)$ & 101.403 \\
\hline & $\mathrm{Cl}(30)-\mathrm{Mn}(29)$ & 2.180 & N(3)-Mn(29)-N(17) & 112.917 \\
\hline & $\mathrm{Cl}(31)-\mathrm{Mn}(29)$ & 2.174 & $\mathrm{~N}(17)-\mathrm{Mn}(29)-\mathrm{Cl}(30)$ & 83.598 \\
\hline & $\mathrm{O}(32)-\mathrm{Mn}(29)$ & 1.870 & $\mathrm{~N}(17)-\mathrm{Mn}(29)-\mathrm{O}(33)$ & 100.124 \\
\hline & $\mathrm{O}(33)-\mathrm{Mn}(29)$ & 1.866 & $\mathrm{~N}(17)-\mathrm{Mn}(29)-\mathrm{Cl}(31)$ & 99.348 \\
\hline & & & $\mathrm{N}(17)-\mathrm{Mn}(29)-\mathrm{O}(32)$ & 162.534 \\
\hline & & & $\mathrm{Cl}(30)-\mathrm{Mn}(29)-\mathrm{O}(33)$ & 81.519 \\
\hline & & & $\mathrm{Cl}(30)-\mathrm{Mn}(29)-\mathrm{Cl}(31)$ & 86.708 \\
\hline & & & $\mathrm{Cl}(30)-\mathrm{Mn}(29)-\mathrm{O}(32)$ & 79.257 \\
\hline & & & $\mathrm{O}(33)-\mathrm{Mn}(29)-\mathrm{Cl}(31)$ & 155.911 \\
\hline & & & $\mathrm{O}(33)-\mathrm{Mn}(29)-\mathrm{O}(32)$ & 74.168 \\
\hline & & & $\mathrm{Cl}(31)-\mathrm{Mn}(29)-\mathrm{O}(32)$ & 83.055 \\
\hline \multirow[t]{6}{*}{$\mathrm{Fe}(\mathrm{II})$} & $\mathrm{C}(2)-\mathrm{N}(3)$ & 1.260 & $\mathrm{C}(2)-\mathrm{N}(3)-\mathrm{C}(4)$ & 115.000 \\
\hline & $\mathrm{C}(2)-\mathrm{N}(7)$ & 1.266 & $\mathrm{C}(2)-\mathrm{N}(7)-\mathrm{C}(8)$ & 123.380 \\
\hline & $\mathrm{N}(7)-\mathrm{Fe}(15)$ & 1.409 & $\mathrm{~N}(7)-\mathrm{Fe}(15)-\mathrm{Cl}(16)$ & 119.113 \\
\hline & $\mathrm{N}(3)-\mathrm{Fe}(15)$ & 1.846 & $\mathrm{Fe}(15)-\mathrm{N}(3)-\mathrm{C}(4)$ & 120.000 \\
\hline & $\mathrm{Cl}(16)-\mathrm{Fe}(15)$ & 2.160 & $\mathrm{Fe}(15)-\mathrm{N}(7)-\mathrm{N}(3)$ & 64.951 \\
\hline & $\mathrm{Cl}(17)-\mathrm{Fe}(15)$ & 2.160 & $\mathrm{Cl}(16)-\mathrm{Fe}(15)-\mathrm{Cl}(17)$ & 91.120 \\
\hline \multirow[t]{6}{*}{$\mathrm{Co}(\mathrm{II})$} & $\mathrm{C}(2)-\mathrm{N}(3)$ & 1.282 & $\mathrm{C}(2)-\mathrm{N}(3)-\mathrm{C}(4)$ & 119.160 \\
\hline & $\mathrm{C}(2)-\mathrm{N}(7)$ & 1.281 & $\mathrm{C}(2)-\mathrm{N}(7)-\mathrm{C}(8)$ & 106.970 \\
\hline & $\mathrm{N}(7)-\mathrm{Co}(15)$ & 1.878 & $\mathrm{~N}(7)-\mathrm{Co}(15)-\mathrm{O}(18)$ & 97.376 \\
\hline & $\mathrm{N}(3)-\mathrm{Co}(15)$ & 1.882 & $\mathrm{Co}(15)-\mathrm{N}(3)-\mathrm{C}(4)$ & 125.317 \\
\hline & $\mathrm{O}(18)-\mathrm{Co}(15)$ & 1.163 & $\mathrm{Co}(15)-\mathrm{N}(7)-\mathrm{N}(3)$ & 65.179 \\
\hline & $\mathrm{Cl}(16)-\mathrm{Co}(15)$ & 2.180 & $\mathrm{Cl}(16)-\mathrm{Co}(15)-\mathrm{O}(18)$ & 166.722 \\
\hline \multirow[t]{6}{*}{$\mathrm{Ni}(\mathrm{II})$} & $\mathrm{C}(2)-\mathrm{N}(3)$ & 1.264 & $\mathrm{C}(2)-\mathrm{N}(3)-\mathrm{C}(4)$ & 120.186 \\
\hline & $\mathrm{C}(2)-\mathrm{N}(7)$ & 1.271 & $\mathrm{C}(2)-\mathrm{N}(7)-\mathrm{C}(8)$ & 115.207 \\
\hline & $\mathrm{N}(7)-\mathrm{Ni}(15)$ & 1.815 & $\mathrm{~N}(7)-\mathrm{Ni}(15)-\mathrm{O}(16)$ & 108.722 \\
\hline & $\mathrm{N}(3)-\mathrm{Ni}(15)$ & 1.846 & $\mathrm{Ni}(15)-\mathrm{N}(3)-\mathrm{C}(4)$ & 122.919 \\
\hline & $\mathrm{O}(17)-\mathrm{Ni}(15)$ & 1.828 & $\mathrm{~N}(7)-\mathrm{Ni}(15)-\mathrm{N}(3)$ & 63.301 \\
\hline & $\mathrm{Cl}(16)-\mathrm{Ni}(15)$ & 2.144 & $\mathrm{Cl}(16)-\mathrm{Ni}(15)-\mathrm{O}(17)$ & 76.316 \\
\hline \multirow[t]{6}{*}{$\mathrm{Cu}(\mathrm{II})$} & $\mathrm{C}(2)-\mathrm{N}(3)$ & 1.290 & $\mathrm{~N}(3)-\mathrm{Cu}(29)-\mathrm{Cl}(31)$ & 104.712 \\
\hline & $\mathrm{C}(2)-\mathrm{N}(7)$ & 1.279 & $\mathrm{~N}(3)-\mathrm{Cu}(29)-\mathrm{Cl}(30)$ & 112.655 \\
\hline & $\mathrm{N}(17)-\mathrm{Cu}(29)$ & 1.353 & $\mathrm{~N}(3)-\mathrm{Cu}(29)-\mathrm{N}(17)$ & 124.741 \\
\hline & $\mathrm{N}(3)-\mathrm{Cu}(29)$ & 1.353 & $\mathrm{Cl}(31)-\mathrm{Cu}(29)-\mathrm{Cl}(30)$ & 92.278 \\
\hline & $\mathrm{Cl}(30)-\mathrm{Cu}(29)$ & 2.170 & $\mathrm{Cl}(31)-\mathrm{Cu}(29)-\mathrm{N}(17)$ & 114.992 \\
\hline & $\mathrm{Cl}(31)-\mathrm{Cu}(29)$ & 2.171 & $\mathrm{Cl}(30)-\mathrm{Cu}(29)-\mathrm{N}(17)$ & 102.823 \\
\hline \multirow[t]{6}{*}{$\mathrm{Zn}(\mathrm{II})$} & $\mathrm{C}(2)-\mathrm{N}(3)$ & 1.373 & $\mathrm{C}(2)-\mathrm{N}(3)-\mathrm{C}(4)$ & 122.097 \\
\hline & $\mathrm{C}(2)-\mathrm{N}(7)$ & 1.500 & $\mathrm{C}(2)-\mathrm{N}(7)-\mathrm{C}(8)$ & 136.829 \\
\hline & $N(7)-Z n(15)$ & 1.565 & $\mathrm{~N}(7)-\mathrm{Zn}(15)-\mathrm{O}(16)$ & 136.826 \\
\hline & $\mathrm{N}(3)-\mathrm{Zn}(15)$ & 1.500 & $\mathrm{Zn}(15)-\mathrm{N}(3)-\mathrm{C}(4)$ & 144.251 \\
\hline & $\mathrm{O}(16)-\mathrm{Zn}(15)$ & 1.890 & $\mathrm{Zn}(15)-\mathrm{N}(7)-\mathrm{N}(2)$ & 86.348 \\
\hline & $\mathrm{O}(17)-\mathrm{Zn}(15)$ & 1.890 & $\mathrm{O}(16)-\mathrm{Zn}(15)-\mathrm{O}(17)$ & 118.507 \\
\hline
\end{tabular}


Fig. 4 3D computational optimized structures of metalAtrazine complexes

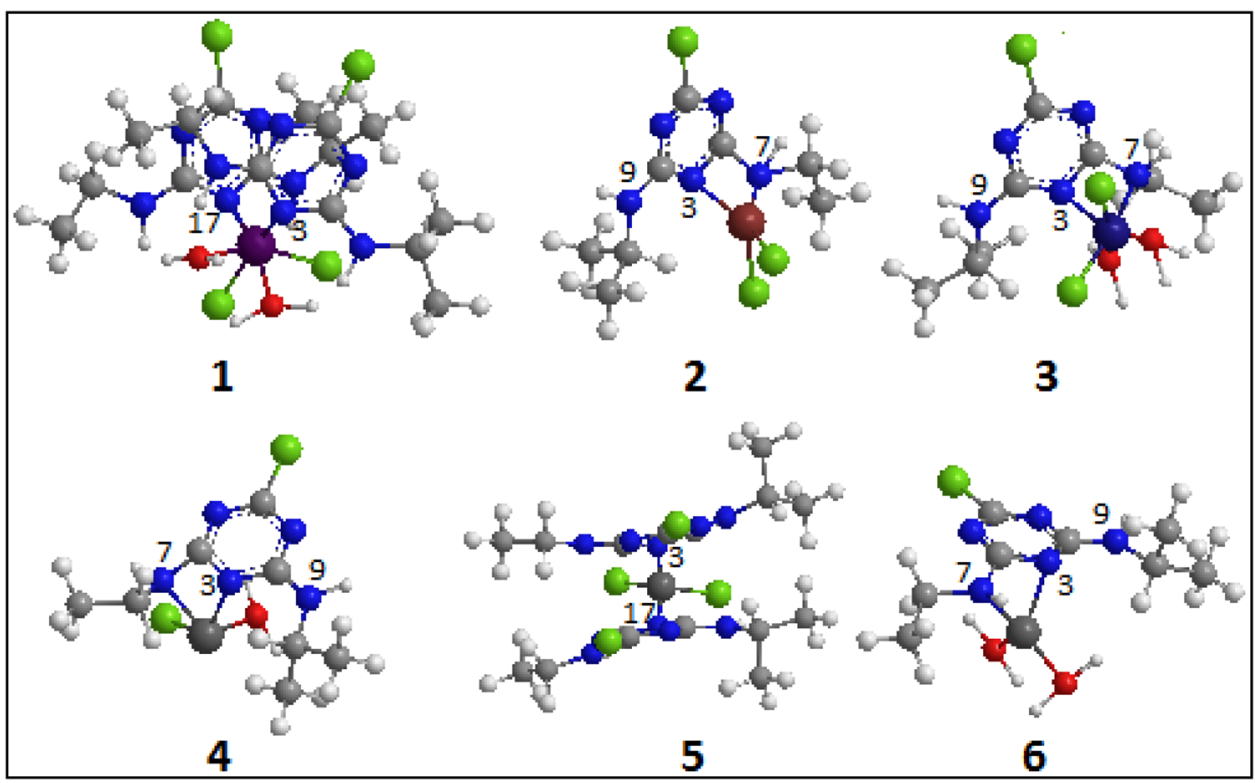

Moghaddamand Foroushani, 2014; Yaremenko et al. 2008). The obtained results are in a good agreement with the experimental results and hence strongly support them.

\section{Conclusion}

The IR spectroscopic studies of six new atrazine-metal complexes have shown that they have different structures consisting of one or two atrazine with one metal ion including variable water and chloride ions. $\mathrm{Mn}$ and $\mathrm{Cu}$ formed 1:2 complexes and coordination occurred through the nitrogen of ring. Remaining metal ions formed the 1:1 complexes by the involvement of nitrogen of ring as well as nitrogen of $\mathrm{NH}$. The numbers of variable water and chlorine molecules were assigned using FTIR spectroscopy and CHN analysis. The apparent correlation between the $\mathrm{M}-\mathrm{N}$ atrazine vibrations and the internal modes of atrazine offers a possible method of predicting metal-atrazine bond strength. The obtained results are supported by 3D molecular modeling of complexes.

Acknowledgments Authors like to acknowledge Lovely Professional University for library and laboratory facilities.

Conflict of interest We have no conflict of interest.

Open Access This article is distributed under the terms of the Creative Commons Attribution License which permits any use, distribution, and reproduction in any medium, provided the original author(s) and the source are credited.

\section{References}

Al-Assy WH, Askalany EI, Mostafa MM (2013) Structural comparative studies on new $\mathrm{Mn}^{\mathrm{II}}, \mathrm{Cr}^{\mathrm{III}}$ and $\mathrm{Ru}^{\mathrm{II}} \mathrm{I}$ complexes derived from 2,4,6-tri-(2-pyridyl)-1,3,5-triazine (TPTZ). Spectrochimica Acta A 116:401-407

Azahari SJ, Rhman MHA, Mostafa MM (2014) Spectroscopic, analytical and DFT calculation studies of two novel $\mathrm{Al}^{3+}$ complexes derived from 2,4,6-tri-(2-pyridyl)-1,3,5-triazine (TPTZ). Spectrochimica Acta A 132:165-173

Bailey GW, White JL, Rothberg T (1968) Adsorption of organic herbicides by montmorillonite: role of $\mathrm{pH}$ and chemical character of adsorbate. Soil Sci Soc Am Proc 32:222-234

Bonora S, Benassi E, Maris A, Tugnoli V, Ottani S, Di-Foggia M (2013) Raman and SERS study on atrazine, prometryn and simetryn triazine herbicides. J Mol Str 1040:139-148

de-Melo CC, Moreira WC, Martins TJ, Cordeiro MR, Ellena J, Guimarães FF, Martins FT (2014) Saddle-shaped macrocycle distortion and symmetry decrease in cobalt (II) meso-tetraphenylporphyrin: structure of a dichloromethane solvate and DFT calculations. J Mol Str 1076:468-474

Dong XW, Wu H, Feng Y, Ma CH, Wang XY, Li YJ (2014) Syntheses, structures and luminescence of silver(I) sulfonate complexes with nitrogen-containing ligands. J Mol Str 1074:516-521

Environmental Protection Agency (EPA), Interim reregistration eligibility decision for atrazine, p 2005 EPA-HQ-OPP-20030072-0002 U.S. Environmental Protection Agency, Washington, DC 2003

Esperdy K, Shillady DD (2007) Simulated infrared spectra of Ho(III) and Gd(III) chlorides and carboxylate complexes using effective core potentials in GAMESS. J Chem Inf Comput Sci 41:1547-1552

Girichev GV, Giricheva NI, Tverdova NV, Pelevina ED, Kuzmina phenylene-bis(salicylideneaminato)zinc(II), Zn(saloph), according to gas-phase electron diffraction and quantum-chemical calculations. J Mol Str 978:178-186

Hakobyan S, Boily JF, Ramstedt M (2014) Proton and gallium(III) binding properties of a biologically active salicylidene acylhydrazide. J Inorg Biochem 138:9-15

Herwig U, Klumpp E, Narres HD, Schwuger MJ (2001) Physicochemical interactions between atrazine and clay minerals. Applied Clay Sci 18:211-222

Kanagathara N, Marchewka MK, Drozd M, Renganathan NG, Gunasekaran S, Anbalagan G (2013) Preparation, crystal $\mathrm{NP}$, Kotova OV (2010) Molecular structure of N, N'-o-

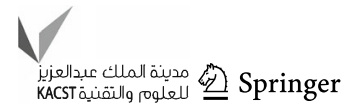


structure, vibrational spectral and density functional studies of bis (4-nitrophenol)-2,4,6-triamino-1,3,5-triazine monohydrate. J Mol Str 1049:345-354

Kumar V, Upadhyay N, Wasit AB, Simranjeet S, Parvinder K (2013a) Spectroscopic methods for the detection of organophosphate pesticides-a preview. Current World Environ 8(2):313-318

Kumar V, Upadhyay N, Singh S, Singh J, Kaur P (2013b) Thin-layer chromatography: comparative estimation of soil's atrazine. Current World Environ 8:469-473

Kumar V, Upadhyay N, Kumar V, Kaur S, Singh J, Singh S, Datta S (2014) Environmental exposure and health risks of the insecticide monocrotophos-a review. J Bio Env Sci 5:111-120

Martin M, Hagege AA, Brunette JP, Leroy M (1998) Use of synergistic extraction for the study of atrazine/metal interactions. Anal Chim Acta 373:161-165

Medlycott EA, Hanan GS, Abedin TSM, Thompson LK (2008) The effect of steric hindrance on the Fe(II) complexes of triazinecontaining ligands. Polyhedron 27:493-501
Meng Z, Carper WR (2000) Effects of hydration on the molecular structure of metal ion-atrazine dimer complexes: a MOPAC(PM3) study. J Mol Struct (Theochem) 531:89-98

Moghaddam FM, Foroushani BK (2014) Experimental and theoretical study of the spectroscopic properties and the preparation of 3-benzyl-2H-pyrano[3,2-c]chromene-2,5(6H)-dione. J Mol Str 1066:235-240

Nakamoto K (1986) Infrared and Raman spectra of inorganic and coordination compounds, 4th edn. Wiley, New York

Prasad R, Upadhyay N, Kumar V (2013) Simultaneous determination of seven carbamate pesticide residues in gram, wheat, lentil, soybean, fenugreek leaves and apple matrices. Microchem J 111:91-97

Yaremenko F, Beryozkina T, Khvat A, Svidlo I, Shishkin O, Shishkina S, Orlov V (2008) 5,7-Substituted thiazolo[2,3a]pyrimidines: synthesis, stereochemistry and crystal structure. J Mol Str 874:57-63 